\title{
Impact of work life balance and stress management on job satisfaction among the working women in public sector banks
}

\author{
Rajesh K. Yadav ${ }^{1, \star}$, Shriti Singh Yadav ${ }^{2, * \star}$ \\ ${ }^{1}$ Department of Management, RKDF College of Engineering, Bhopal (M.P.), India \\ ${ }^{2}$ Research Scholar, Barkatullah University, Bhopal (M.P.), India \\ ${ }^{*, * * E-m a i l ~ a d d r e s s: ~ d r r a j e s h k y a d a v @ y a h o o . c o m, ~ s h r i t i s i n g h @ g m a i l . c o m ~}$
}

\begin{abstract}
In today's competitive environment, work life balance and stress management for women employees is highly desirable and if there is no job satisfaction and regularity in life, it can create a problem for working women. Stress of work life balance is seen in every corner of the world which occurs to everyone. It becomes critical when there is no job satisfaction. Work life balance requires, getting stability between professional work and personal work, so that it reduces friction between official and domestic life. The final performance of any organization depends on the performance of its employees, which in turn depends on several factors. These factors can be related to job satisfaction. An empirical study is conducted among the working women of public sector banks with the purpose of assessing impact of work life balance and stress management on job satisfaction. Secondary data is used to understand and conclude the study. Observation during the study suggests that WLB and Stress management can be achieved by the factors responsible for job satisfaction such as: encouraging social groups, accommodating working conditions, mentally challenging work, impartial rewards and employee oriented policies etc. To conclude the study, it is suggested that Work-Life Balance and stress management is not a problem to be solved, it is a constant issue to be managed.
\end{abstract}

Keywords: Family; Employee's satisfaction; Stress; Performance; Productivity and Rewards etc.

\section{INTRODUCTION}

India is a rising economy and at present most of the women is engaged in working somewhere in organizations. So, this study focuses on working women who are working in public sector banks. The vital consideration of this study is to examine the impact of work life balance and stress management on job satisfaction. Work determines a person's worth and place in society and it influences one's mental identity and sense of well being. The term "work" is being used to paid work or employment. Work establishes one in the community of human kind. It links a person to others, advances the goals of culture, and gives purpose to one's existence. Work is a purposeful human activity which is directed toward the satisfaction of human needs and desires. It is obvious that work needs to be satisfying the job for a mutual beneficial relationship between employee and employer. 
In Indian context, the concern over work-life balance and Stress management is gradually becoming a common talk especially when it comes to job satisfaction for women employees. Work life balance is a state of balance in which the demand of both professional and personal life is equal. Each role having different set of demands and when such role demands overlap, multiple problems are faced and it creates a lot of stress. People use the term stress to describe the feeling, when it all seems too much, when they are overloaded and don't feel that they are able to meet all the demands and challenges placed upon them. The causes of stress are known as stressors and there are exactly hundreds of different types of stressors. Any event in life that a person finds threatening, difficult to cope with or causes excess pressure can be a potential cause of stress. In reality life and work over-lap and interact and facilitate stress. Stress related a problem reduces productivity and morale. On the other hand if there is no job satisfaction for women employees it causes heavy stress and work life imbalance. In designing the stress and work life policies employer should think that the commitment of employees can make the difference between those companies which compete at the marketplace and those which cannot. An unbiased life for women is one where they extend their energy and effort between key areas of importance.

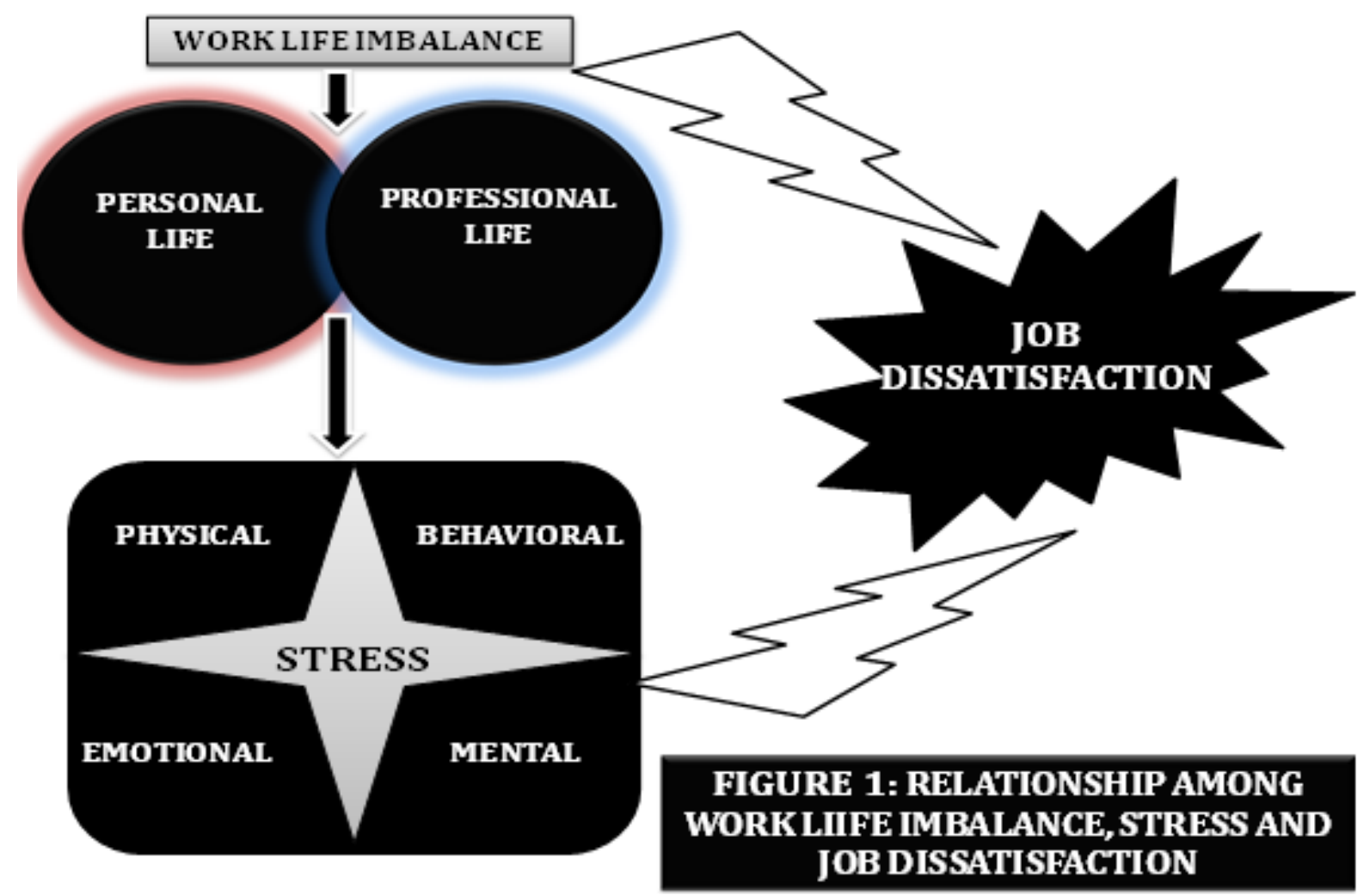

Employees are greatest resource of an organization. Attracting and retaining the right people is critical to the success of an organization. When it comes to human environment, it focuses on human aspects that influence an employee's performance and job satisfaction. Job satisfaction has been defined as the amount to which employees have a positive sentimental direction towards employment by the organization. Job satisfaction creates innovative ideas among the employees. Individuals may become more loyal towards the organization. 
Employees will be more satisfied if they get what they expected with efficient work life balance and stress management policies. Lots of researches have been conducted on the areas of work life balance, stress and job satisfaction. But a little research have been done on correlating all of these three variables, in attempts to produce trustworthy, convincing information on working women of public sector banks. Bank administrations must be able to manage their female staff while formulating their policies, otherwise; Banks will be facing a strict shortage of intellectuality, both quantitatively and qualitatively. Sensibly it is the satisfied worker who shows the maximum effectiveness and efficiency in his work $[1,5,7,8]$.

\section{WORTH OF COLLISION OF WORK LIFE BALANCE AND STRESS WITH JOB SATISFACTION TO THE WOMEN EMPLOYEES}

Under this heading the focus is placed on the fact that when WLB and Stress met with the job performance then job dissatisfaction comes as an outcome. Since there is no single size fits all Work Life balance and stress management policies. Different stages of life and career have different Stress, Work Life balances and satisfaction needs. Different business needs require different commitments and requirements. An imbalance is created when dissonance occurs between work time and personal life time which results in stress. Apart from it if an employee achieve the desired results but didn't get desired reward, creates a dissatisfaction and heavy stress especially in the case of women employees.

The working area of Women in India is shifting at incredible pace due to, progressive fall in trade barriers, modern advances in technologies, internationally organized market place, cut throat competition, business competition and changing family and population patterns. These factors bring out tense anxiety into the life of the women and then it is magnified many times if both the husband-wife is working and they have children of growing age and old age parents. This regular worry can cause disorder on the psychological comfort of the women due to a feeling of diminished control over one's life and a hopeless perception that there is never enough time to have a sensible stability and balance in life due to stress. The results of poor stress management and work life policies include decreased proficiency, higher absenteeism rates, low employee morale, unproductive team work and employee health related problems. Apart from it there are variety of factors that make women employee feel positive or negative about their job. Moreover, some employees may be satisfied with a few aspects of their work but dissatisfied with all other aspects. Factors that lead to positive or negative perceptions of work life imbalance and stress have their own impact on job satisfaction.

This mental stress for women lead to physical stress and cause ill health, headache, gastritis, body ache, de-motivation, low morale etc. or lead to long term cardiac problems, high blood pressure, diabetes or other psychiatric problems and low job performance etc. All these problems generate work life conflict, intense stress and job dissatisfaction especially for women employees. Banks can implement the necessary measures to create healthy work life management and stress programs by effectively assessing stressors, causes for work life imbalance and job dissatisfaction that will be the differentiating factor of a mediocre business to increase the performance and productivity.

The issues that are discussing here are not impossible, but it does take some consistent effort and reevaluation on an ongoing basis. Work can dominate your life. Recognizing what is important and necessary and striving for what is valued will make a work-life balance and 
stress management feasible. Utilizing management skills will enable an employee to have a job satisfaction and coping up with stress, work and home life.

There are many causes for stress in the workplace and the possibility for eliminating all of them is impossible. It also may be harmful. Sometimes stress provides positive outcomes. Stress can sometimes motivate and refresh and enable people to achieve more; the key appears to be in how individuals are able to cope with it. The banking sector can help working women by implementing organizational strategies to control or reduce some of the major causes of stress. It can be said that with the change of satisfaction determinants, level of job satisfaction also varies $[3,9,10,12-16]$.

\section{RESULTS OF WORK LIFE IMBALANCE}

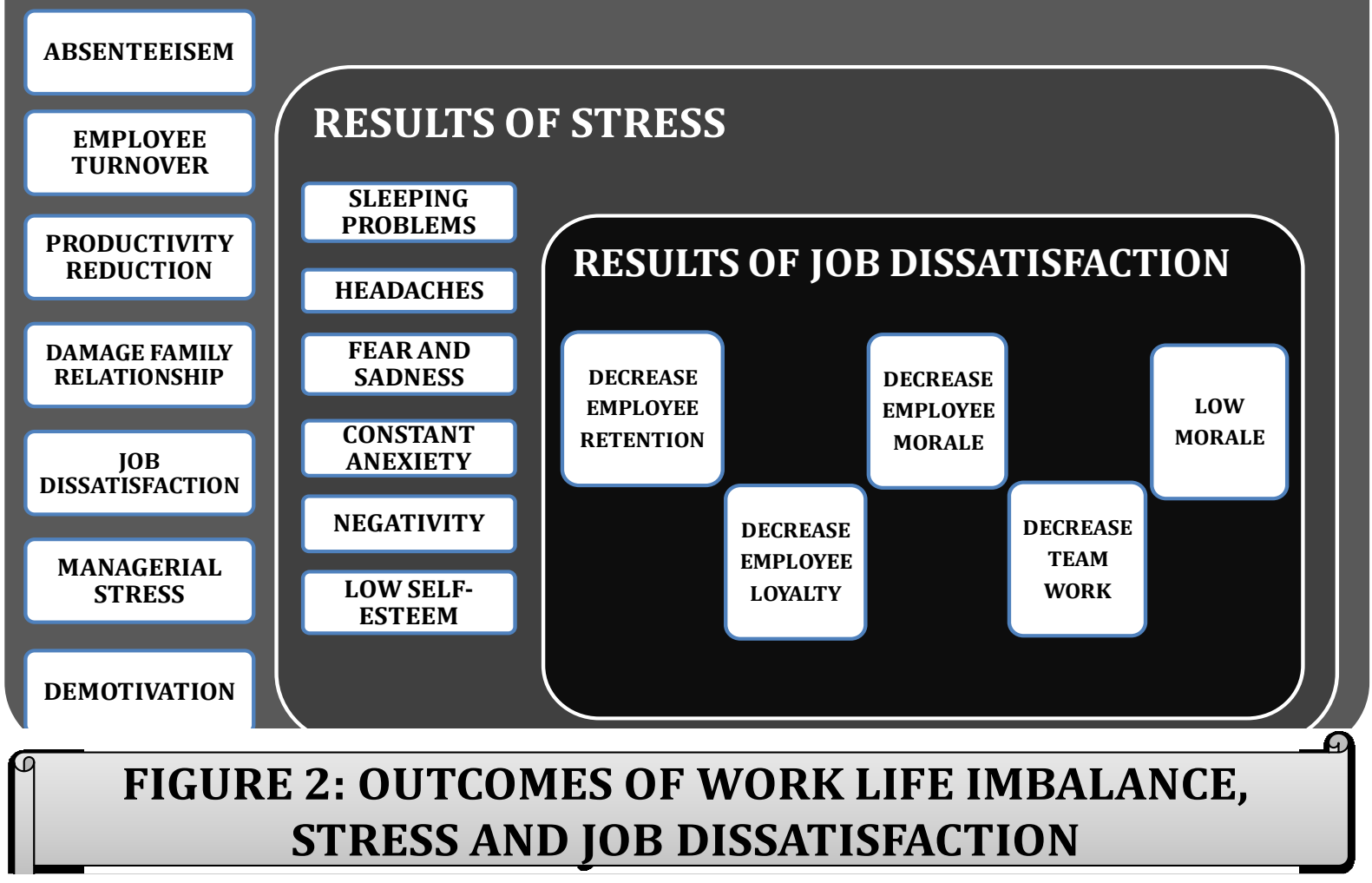

\section{IMPACT OF WORK LIFE BALANCE AND STRESS ON JOB SATISFACTION}

- Recognition is the part of job satisfaction. It is an act of notice, praise, or blame supplied by one or more superior, peer, colleague, management person, client, and/or the general public. Failure in getting recognition leads stress and poor job satisfaction.

- Workers promptness, Teamwork, Customer service, work direction accountability, group behavior, peer communication and management qualities of workers are reduced due to lowered self-worth and morale in workers due to stress and conflict in work life balance. 
- Seniority demands the promotion and promotion facilitates mental satisfaction. It refers to designate an actual change in upward direction in job status. The promotion to the next level will result in positive changes such as pay, autonomy and supervision etc.

- Creativeness, learning and originality of worker are disgustingly damaged due to lowering of work related enthusiasm among workers.

- Workers having problem balancing work roles and family roles set bad standard in the company work setting and often upset the friendly work ambience and facilitate stress.

- Workers problems get reflected negatively on company's turnover, operating profit and balance sheet.

- Highest monetary satisfaction for, specially, women employee is monthly salary or pay. These are the sequences of events in which compensation plays a major role. There is no doubt that monetary rewards may play a very influential role in determining job satisfaction. If salaries are not market oriented, this can lead to dissatisfaction.

- Physical working conditions and facilities are equally significant for job satisfaction of women employees. Apart from it company policy and administration plays an important role in satisfaction. These should be framed in keeping the view of employee's needs and desire

- Women employees facilitate stress on interpersonal relationship within the premises majorly with the female colleagues. It involves relationships with superiors, subordinates, and peers or colleague. If the employee experiences the healthy relationship with others within the organization, so it will boost the morale and satisfaction toward the job and lead to the higher productivity.

- A certain amount of stress can be mentally stimulating but too much can affect our thinking ability. Thoughts may become jumbled and confused. Although the job is right but it creates dissatisfaction.

- People respond to stress in many different ways. Common emotional effects are irritability, impatience, anger, frustration, fear, anxiety, self-doubt, panic and despondency, feelings of inadequacy, insecurity, hopelessness, unhappiness, emotional withdrawal and depression.

- Stress can change people's behavior towards one another. We may become less sociable, less caring, more hostile and insensitive towards others. When stress is accompanied by anger we may become less tolerant, fly off the handle easily and provoke rows and which adversely affects job satisfaction $[2,4,6,11]$. 




\section{CONCLUSIONS}

Nowadays we see women working in almost all types of professions demonstrating that there is no gender difference in work. In fact many organizations say that women are playing a vital role in uplifting the organization. This is a positive development that women are making their presence in different walks of life. On the other hand, for every woman there is one more background to manage, which is home and personal life. Today with increasing demands at work place, the interface between work life and personal life assumed significance which demands more attention. The pressures of the work or personal life can lead to stress. According to studies, it has been found that such situation affects person's health both physiologically and psychologically. Therefore, it is important for employees to maintain a healthy balance between work and their private lives with less stress and high degree of job satisfaction.

For the employers, Work-life balance and increasing stress of employees will be an important input in designing appropriate policies for employees. Positive thinking is the key to success; take control of your stress and anxiety by learning effective techniques to combat it. When you are relaxed, you can view each task as a positive challenge, and use stress as a spur to help you to carry it out giving you a relaxing glow of achievement afterwards. The term 'Satisfaction' refers to the simple feeling/state associated with the attainment of his/her objectives. Various theories like Maslow's Need Hierarchy Theory, Herzberg's MotivationHygiene Theory, and Vroom's Expectancy Model have been extended to describe the factors 
responsible for the Job Satisfaction of the employees in the organization. Broadly we can say that an employee's 'Job Satisfaction' is related to a number of variables such as age, occupational level, size of the organization, organizational climate, educational qualifications, educational and economic background, size of the family, gender of the employee, etc. Satisfaction with one's job can affect not only motivation at work but also career decisions, relationships with others and personal health.

Those who work in a profession that is extremely demanding and sometimes unpredictable, have job dissatisfaction. There are many causes for dissatisfaction at the workplace and the possibility for eliminating all of them is impossible. Sometimes dissatisfaction provides positive outcomes. This can sometimes motivate and energize and enable people to achieve more; the matter is how employees as individuals are able to cope with it. While concluding, it can be said that with the change of satisfaction determinants, level of job satisfaction also varies.

\section{References}

[1] Gururaja, Maiya Umesh, Sanatombi Elsa, George Anice, International Journal of Humanities and Social Science Invention 2(3) (2013) 52-54.

[2] Hughes Jaanna, Bozionelos Nikos, Personnel Review 36(1) (2007) 145-154.

[3] Jamal Nazrul Islam, Haradhan Kumar Mohajan, Rajib Datta (2012): “A Study on Job Satisfaction and Morale of Commercial Banks in Bangladesh", IJER, Jul - Aug, pp: 153-173.

[4] Latif Khalid, Shahid Muhammad Naeem, Sohail Naeem, Shahbaz Muhammad, Interdisciplinary Journal of Contemporary Research in Business 3(8) (2011) 235-242.

[5] Kumari Geeta, Pandey K. M., International Journal of Innovation Management and Technology 2(5) (2011) 360-367.

[6] Kumari Lalita, IJEMR 2(2) (2012) 1-13.

[7] Kamal Raj, Sengupta Debashish, Prajnan 37(3) (2008) 229-245.

[8] Rao VSP, (2009): "Human resource management - Text and cases", Excel books New Delhi, pp. 299-306.

[9] Sakthivel Rania, Kamalanabhanb \& Selvarania, Serbian Journal of Management 6(1) (2011) 85-96.

[10] Shahu Rashmi, Gole S. V., AIMS International Journal of Management 2(3) (2008) 237-246.

[11] Syed Aktharsha U., Anisa H., JMIJHRR 1(1) (2011) 18-32.

[12] Varatharaj V., Vasantha S., International Journal of Multidisciplinary Research 2(3) (2012) 450-458.

[13] Rajesh K. Yadav, Nishant Dabhade, International Letters of Social and Humanistic Sciences 7 (2013) 1-22. 
[14] Rajesh K. Yadav, Nishant Dabhade, International Letters of Social and Humanistic Sciences 5 (2014) 44-62.

[15] Rajesh K. Yadav, Nishant Dabhade, International Letters of Social and Humanistic Sciences 10(2) (2014) 181-201.

[16] Rajesh K. Yadav, International Letters of Social and Humanistic Sciences 12 (2014) 16. 